فعالية برنامج تدريبي في تنمية بعض مهارت تنظيم الأت لاى الأطفال المكفوفين أ.د عبد العمبي محمد علي أ.د وفاء محمد عبد الجواد أ. نجوى حمدي عليوه الشرقاوي
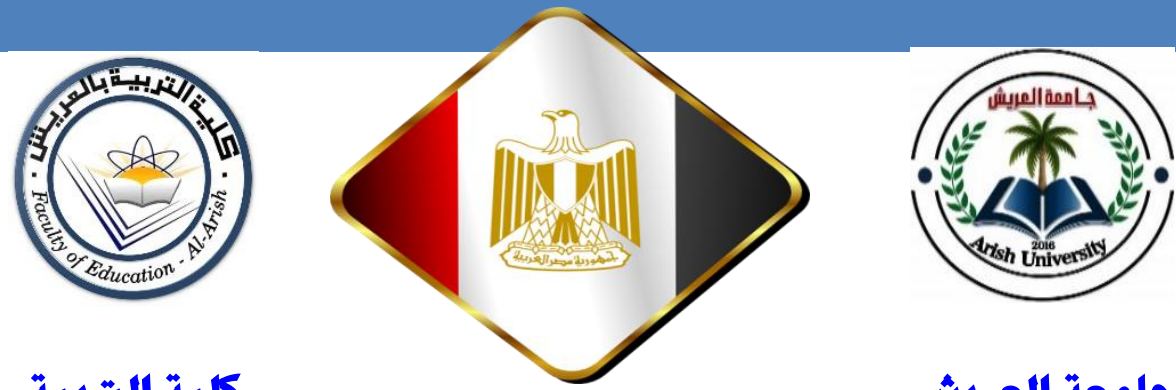

كابة التزبية

بامعة العربشي
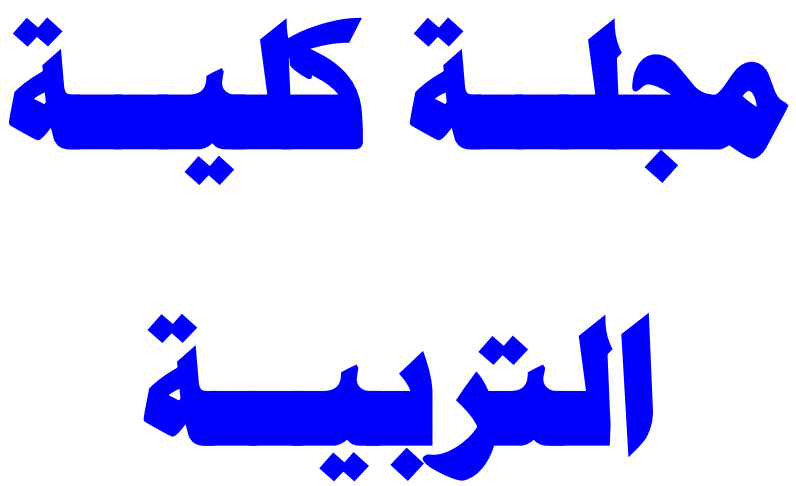

علمية محكمة ربع سنوية

(السنة الثامنة - العدد الحادي والعشرون -يناير •؟+؟م)

j_foea@aru.edu.eg 


\section{الإشراف العــــام}

\begin{tabular}{|c|c|}
\hline عمبـد الكثية & أ.د. كمال عبد الوهاب أحمد \\
\hline وكيل الكيّة للاراسات العليا والبحوث & أ.م.د عصام عطية عبد الفتاح \\
\hline
\end{tabular}

\section{هينئة التمريز}

\begin{tabular}{|c|c|}
\hline رئيس التحرير & أ.د. محمد رجب فضل الله \\
\hline عضو & د. كمال طاهر موسى \\
\hline عضو & د. محمد علام محمد طلبة \\
\hline عضو & د. ضياء أبو عاصي فيصل \\
\hline
\end{tabular}

\section{الإشراف المالي والإداري}

\begin{tabular}{|c|c|}
\hline المسؤول المالي & أ. محمد إبراهيم محمد عريبي \\
\hline المسؤول الإداري & أ. أسماء محمد علي الثاعر \\
\hline
\end{tabular}




\section{قواعد النشر بهجلة كلية التربية بالعريش}

ا ـ نتشر المجلة البحوث والدراسات التي تتوافر فيها الأصالة والمنهجية السليمة على ألا

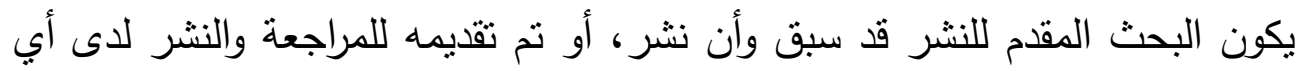
جهة أخرى في نفس وقت تقديمه للمجلة. r. تُقبل الأبحاث المقدمة للنشر بإحدى اللغتين: العربية أو الإنجليزية.

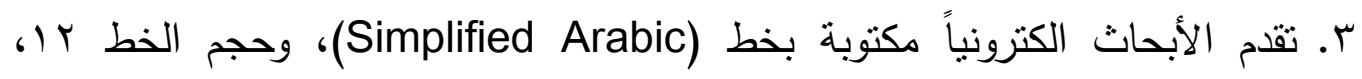
وهوامش حجم الواحد منها ه.بسم، مع مراعاة أن تتسق الفقرة بالتساوي ما بين الهامش الأيسر والأيمن (Justify). وترسل إلكترونياً على شكل ملف مانف ( Microsoft)

. (Word

ء. يجب ألا يزيد عدد صفحات البحث المُحكم بما في ذلك الأشكال والرسوم والمراجع والجداول والملاحق عن (Y0) صفحة. (الزيادة بحد أقصى .1 صفحات برسوم إضافية). ولا يزيد البحث المُستل عن ( • r صفحة ) (الزيادة بحد أقصى ه صفحات برسوم إضافية).

ه. يقدم الباحث ملخصاً لبحثه في صفحة واحدة، تتضمن الفقرة الأولى ملخصاً باللغة

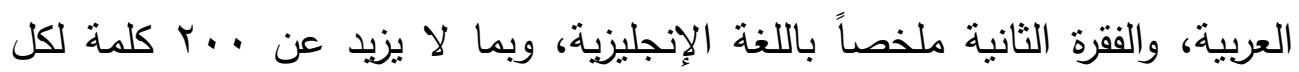
منها. 7. يكتب عنوان البحث واسم المؤلف والمؤسسة التي يعمل بها على صفحة منفصلة ثم يكتب عنوان البحث مرة أخرى على الصفحة الأولى من البحث. لهن V. يجب عدم استخدام اسم الباحث في منن البحث أو قائمة المراجع ويتم استبدال الاسم بكلمة "الباحث"، ويتم أيضاً التخلص من أية إثنارات أخرى تدل على هوية المؤلف.

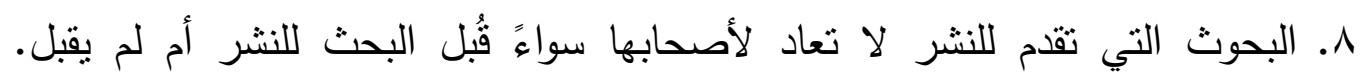
وتحتفظ هيئة التحرير بحقها في تحديد أولويات نشر البحوث. 
9. لن ينظر في البحوث التي لا تتقق مع شروط النشر في المجلة، أو تلك التي لا

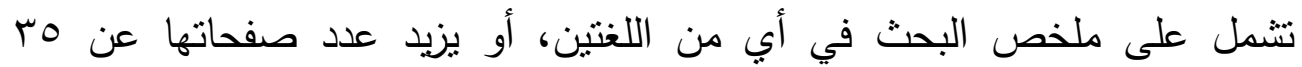

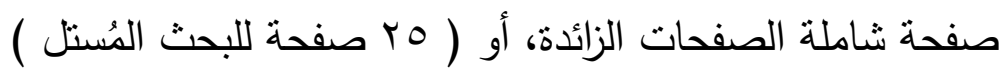
• • بقوم كل باحث بنسخ وتوقيع وإرفاق إقرار الموافقة على اتفاقية النشر . 11. يسهم الباحث في تكاليف نشر بحثه، ويتم تحويل التكلفة على الحساب الخاص بالمجلة. يجب إرسال صورة عن قسيمة التحويل أو دفع المبلغ، مع البحث الكترونيا. التكاليف تشمل: مكافأة التحكيم، وتكلفة الطباعة والنشر ، والحصول على نسخة من العدد، وعدد ( 0 ) مستلات من البحث المُحكم، و ( ( ) من البحث المُستل. r ا. يتم نشر البحوث أو رفض نشرها في المجلة بناءً على تقارير المحكمين، ولا يسترد المبلغ في حالة رفض نشر البحث من قبل المحكمين. با. تُمنح كل باحث إفادة بقبول بحثه للنشر بعد إتمام كافة التصويبات والتعديلات المطلوبة، وسداد الرسوم المقررة.

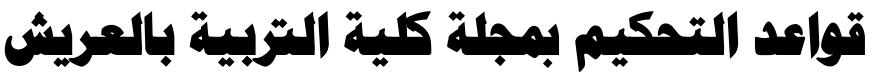

فيما يلي القواعد الأساسية لتحكيم البحوث المقدمة للنشر بمجلة كلية التربية بالعريش

\section{القواعد عامهة:}

1. مدى ارتباط موضوع البحث بمجال التربية. r. مدى مناسبة الدراسات السابقة، وإبرازها لرؤى متعددة. r. درجة وضوح أسئلة وأهداف البحث. ع. مستوى تحديد عينة ومكان البحث.

ه. درجة إتباع البحث لمعايير التوثيق المحددة في دليل رابطة علم النفس الأمريكية، العدد السادس.

T. احتواء قائمة المراجع على جميع الدراسات المذكورة في منن البحث والعكس أيضاً

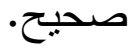

v. حدود الدراسة، وتبريراتها. 
^. سلامة تقرير البحث من الأخطاء اللغوية المتعلقة بالنحو والإملاء وكذا المعنى. 9. تكامل جميع أجزاء تقرير البحث، وترابطها بشكل منطقي.

قواعد المكم على منهمية البمث:

ا. تحديد الفترة الزمنية للبحث. r. تحديد منهجية مناسبة للبحث.

r. تبرير إجراءات للاختيار في حالة دراسة الأفراد أو الجماعات. ملات ع. تضمين البحث إطاراً نظرياً واضحاً.

ه. توضيح الإجراءات المتعلقة بالجوانب المهنية الأخلاقية مثل: الحصول على موافقة المشاركين المسبقة.

\section{قواعد تصكيم الإجزاكات:}

1. شرح وسائل جمع المعلومات بوضوح، والعمليات المتبعة فيها. r. تحديد وشرح المتغيرات المختلفة.

r. ترقيم جميع الجداول والأشكال والصور والرسوم البيانية بشكل مناسب وتبويبها والتأكد من سلامتها. ع. شرح عملية التحليل المتبعة ومبرراتها، والتأكد من اكتمالها وسلامتها.

\section{قواعد المكم عاتى النتائه:}

ا . عرض النتائج بوضوح.

r. توضيح جوانب الاختلاف في حالة تعارض نتائج البحث مع نتائج الدراسات السابقة. r. اتساق الخاتمة والتوصيات مع نتائج البحث. 
محتويات العدد ( IV)

\begin{tabular}{|c|c|c|c|}
\hline \multicolumn{2}{|r|}{ هيئة التحريز } & \multicolumn{2}{|l|}{ السنة السابعة } \\
\hline الصفحات & الباحث & عنوان البحث & الرقم \\
\hline \multicolumn{4}{|c|}{ مقال العدد } \\
\hline$\varepsilon r-10$ & 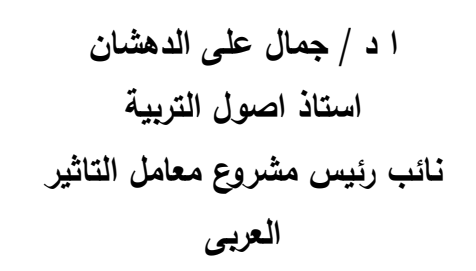 & تقييم وتصنيف الاتتاج العلمى المنشور & 1 \\
\hline \multicolumn{4}{|c|}{ بحوث ودراسات محكمة } \\
\hline $\mid r Y-\varepsilon V$ & 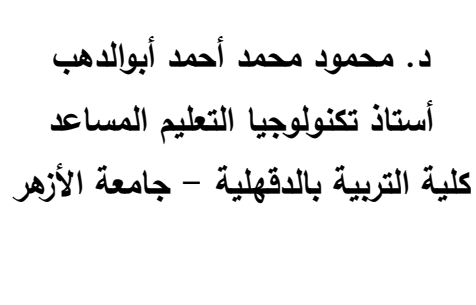 & 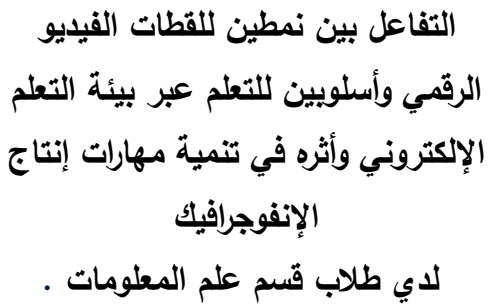 & 1 \\
\hline $19 V-1 M r$ & 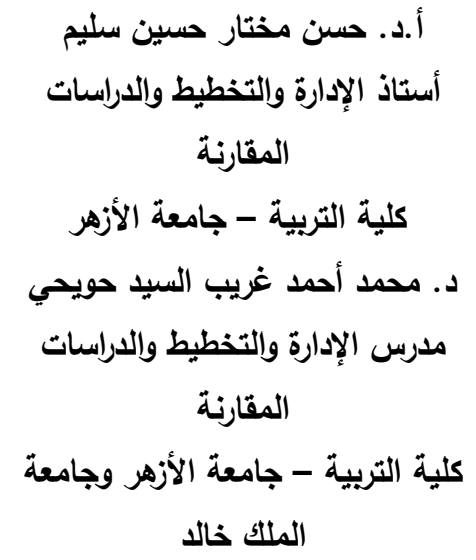 & في ضوير الأداء المؤسسي بجامعة الأزهر & $r$ \\
\hline$r V 1-199$ & 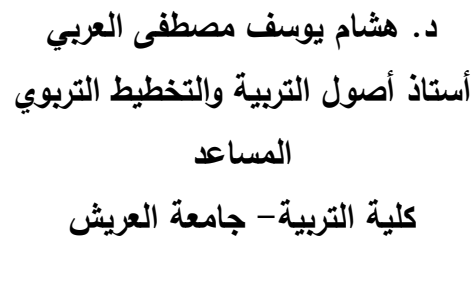 & استراتيجية مقترحة لتفعيل دور جامعة & $r$ \\
\hline
\end{tabular}


بحوث مستلة من رسائل ماجستير ودكتوراه

\begin{tabular}{|c|c|c|}
\hline$r \cdot \Delta-r v \Delta$ & 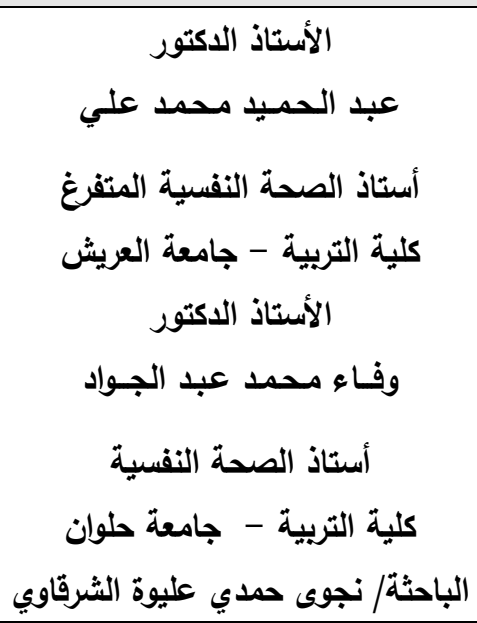 & 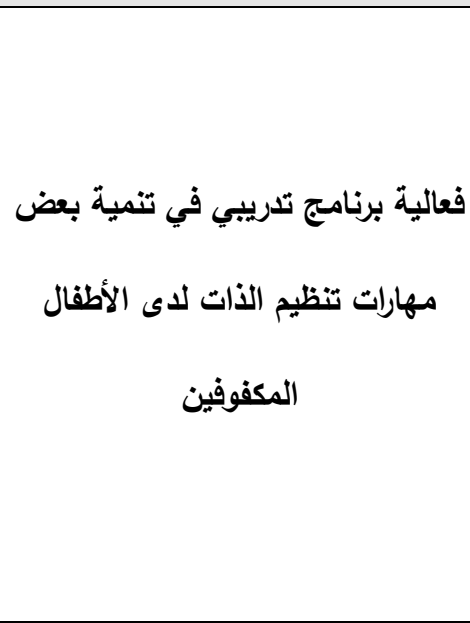 \\
\hline$r r \wedge-r \cdot v$ & 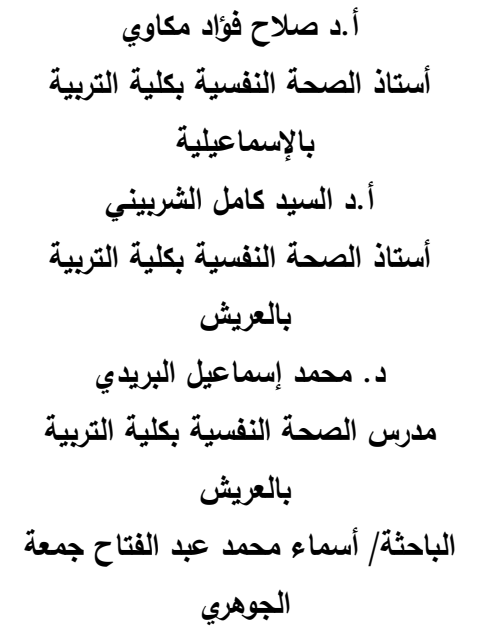 & الأكاء الروحي والتذفق النفسي لاى \\
\hline$r v \cdot-r r q$ & 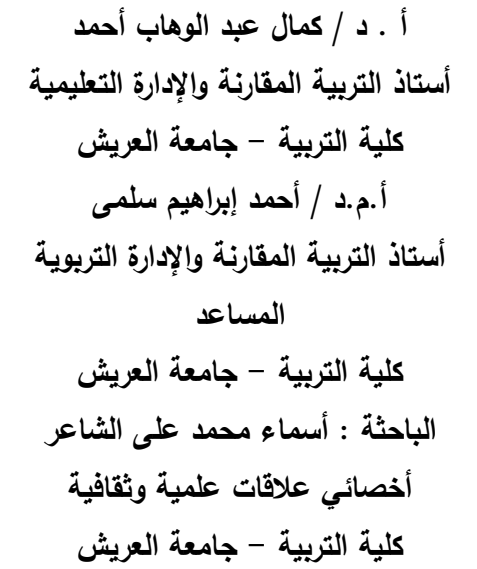 & تحسين أداء القيادات الإدارية بجامعة \\
\hline
\end{tabular}




\section{البحث الأول}

فعالية برنامج تدريبي في تنمية بعض مهارات تنظيم الذات لاى الأطفال المكفوفين

\section{إعـــــــ}

الأستاذ الاكتور

وفـاء محمد عبد الجـواد

أستاذ الصحة النفسية

مدير مركز الإرشاد النفسي ورعاية ذوي الاحتياجات الخاصة

كلية التربية - جامعة حلوان
الأستاذ الاكتور

عبد الحمبيا محمد علي الي أستاذ الصحة النفسية المتفرغ ومدير مركز الإششاد النفسي كلية التربية جامعة العريش

الباحثة / نجوى حمدي عليوة الشرقاوي 
فعالية برنامج تدريبي في تنمية بعض مهارات تنظيم الذات لاى

\title{
الأطفال المكفوفين
}

\author{
إعــــــداد \\ الأستاذ الاكتور \\ الأستاذ الاكتور \\ وفـاء محمد عبد الجـواد \\ عبد الحمـيا محمد علي \\ أستاذ الصحة النفسية \\ أستاذ الصحة النفسية المتفرغ \\ مدير مركز الإرشاد النفسي ورعاية \\ ومدير مركز الإرشاد النفسي \\ ذوي الاحتياجات الخاصة \\ كلية التربية التية \\ كلية التربية - جامعة حلوان \\ جامعة العريش التهرئ
}

الباحثة /نجوى حمدي عليوة الشرقاوي

ملخص البحث:

هدفت الدراسة إلى التحقق من فاعلية برنامج تدريبي قائم على الأنشطة في

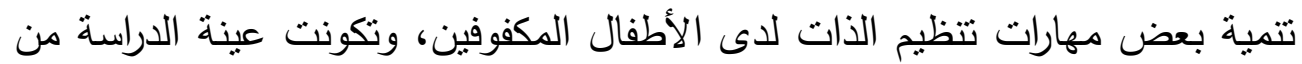

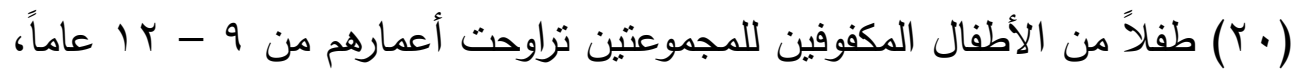
واستخدمت الباحثة اختبار الذكاء ستانفورد بنية (الصورة الرابعة) تعريب لويس مليكة

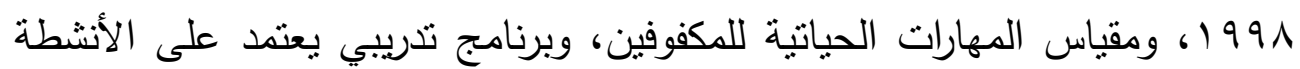
(من إعداد الباحثة). وأسفرت نتائج الدراسة عن فاعلية البرنامج التدريبي في تتمية بعض مهارات تتظيم الذات لدى الأطفال المكفوفين. 
The current study aimed at verifying the effectiveness of a training activities program based on developing some of selfregulation for blind children. The sample of the study included (20) children of the total blind with age range from (9 to 12) years old. Researcher employed the fifth edition of StanfordPenee of intelligence fourth image (Arabize by Louis Malika) and life skills for blind children scale for blind children and a training program and socioeconomic level scale (Abd El-Aziz El-Shakhes, 2006); all of which are prepared by the researcher. The study proved the effectiveness of a training program in developing some self-regulation skills for blind children. 
فعالية برنامج تدريبي في تنمية بعض مهارات تنظيم الذات لاى الأطفال

المكفوفين

مقدمة:

تعد مرحلة الطفولة من أهم المراحل التي يمر بها الإنسان في حياته والركيزة

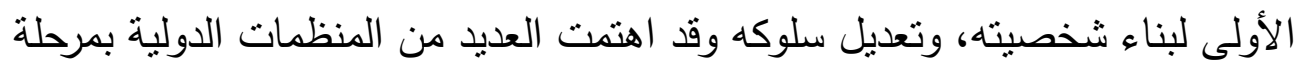
الطفولة للوصول إلى النمو المتكامل للطفل، ولم يقتصر هذا الاهتمام علي الأطفال الأسوياء فقط، بل اتسع ليثمل الأطفال ذوي الاحتياجات الخاصة، كما تشير تقارير منظمة الصحة العالمية إلى أن الإعاقة البصرية تمثل نسبة كبيرة من أعداد المعاقين

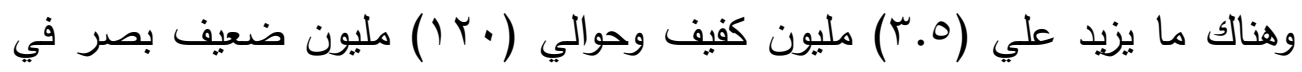
العالم وأن نسبة انتشار كف البصر في الاعمار أقل من (10) عاما المكفوفين كلياً يمنل حوالي 10 مليون طفل، وأن نسبة انتشار كف البصر تختلف من دولة إلى الى أخرى وأن حوالي ، ^^\% من المعاقين بصريا يوجدون في دول العالم الثالث وتزداد نسبة انتشار الإعاقة البصرية مع تقدم العمر وخاصة في الدول التي تفتقر إلى الرعاية الصحية المناسبة.

لذا يكمن ضرورة الاهتمام بهم؛ وذللك لكون الكفيف عنصر من عناصر المجتمع، والذي تسبب إعاقته خلا في البناء الاجتماعي لمجتمعه، وعقبة في طريق

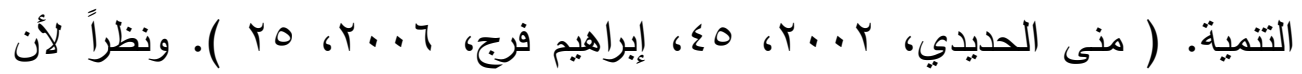
الأطفال المكفوفين كليا أكثر ثأثراً بالإعاقة في جوانب عديدة منها مهارات التواصل ومهارات الاستقلال، ومهارات الحركة والتوجه، ومهارات التعلم الذاتي وجودة الحياة النفسية والاجتماعية وإن امتلاك الاطفال للمهارات الحياتية وتتميتها أصبح ضرورة ودهات ودهات ملحة ومهمة أساسية سواء للأسرة أو المدرسة من خلا عملية التتشئة الاجتماعية لهم، مما يساعدهم علي تكيفهم مع مجتمعهم، وتتمية قدراتهم علي حل المشكلات

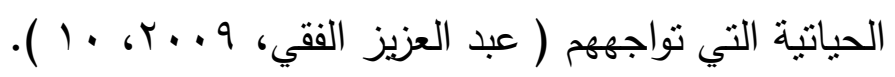
والمهارات الحياتية تساعد الاطفال المكفوفين علي تنشيط العادات الاجتماعية، وتوجهم إلي حل المشكلات وتكسبهم القدرة علي التعبير عن الذات، كما تدربهم علي 
تقبل الهزيمة وتوفر الفرص للشعور بالإنجاز، كما تكسبهر مهارات الاعتماد علي الذات وتوفر الفرص للشعور بالإنجاز مما يساعدهم على سرعة تكيفهم مع زملائهم

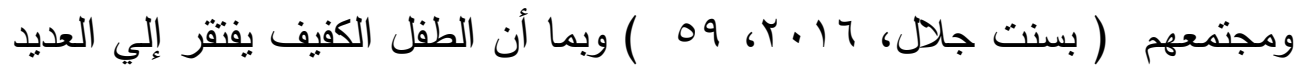
من المهارات الحياتية التي تؤدي إلي بعض المشكلات السلوكية مما يجعل الحاجة ملحة لتقديم محتوي ذي جودة عالية لتيسير الأنشطة وإتاحة المواد التعليمية لهم وتعزز مشكلاتهم وزيادة الفرص المتاحة لهم.

والوعي باستراتيجيات تتظيم الذات والتدريب عليها بالنسبة للأطفال المكفوفين ينعكس إيجابيا علي التحصيل، ويجعل الفرد قادرا علي تحديد أهداف سواء في عملية التعلم أو حياته الثخصية ويسعي إلي تحقيقها بفعالية ذاتية ( جابر عبد الحميد، إيمان

$$
\text { مشكلة الدراسة: المقصود، مني بدوي، ـ ( ـ ب، ع م). }
$$

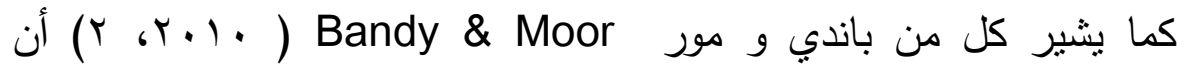

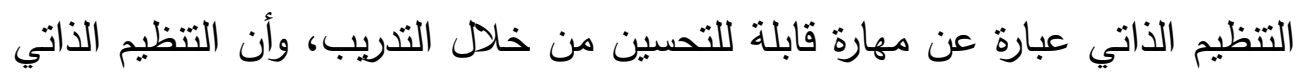
ليس عاملا موروثا ولا قدرة فطرية وإنما مهارة تكتسب بالخبرة والتدريب مثل أب مهارة أخري حتي تصبح تكوينا أصيلا في شخصية الفرد تساعده في المهام الحياتية المختلفة.

فمن هذا المنطلق تتلخص مشكلة الدراسة الحالية في الأسئلة التالية: (1) هل يؤدي البرنامج التدريبي إلي تتمية بعض مهارات تتظيم الذات مثل كفاءة

الذات، التحكم الذاتي، تقييم الذات لدي عينة الدراسة بعد التطبيق ؟ (Y) هل يمتد ثأثير البرنامج في تتمية بعض مهارات تتظيم الذات لدي عينة

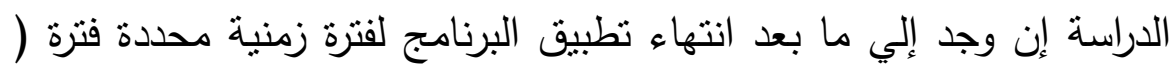

$$
\text { أهداف الدراسةة: المتابعة ) ؟ }
$$

التحقق من مدي فاعلية البرنامج التدريبي المستخدم في الدراسة لتتمية بعض مهارات تتظيم الذات لدي الاطفال المكفوفين من سن 9 - r I عاما. 
أهمية الدراسة: يمكن إيجاز أهمية الدراسة على المستويين النظري والتطبيقي على النحو التالي: أ - الاهمية النظرية:

1-ندرة الدراسات التي تتاولت تتظيم الذات للأطفال المكفوفين وذللك في حدود علم الباحثة وهو ما يعكس حداثة الموضوع ونقص المعلومات فيه. r- تتمية بعض مهارات تتظيم الذات مثل كفاءة الذات والتحكم الذاتي وتقييم الذات يساعد الاطفال المكفوفين علي أن يكونوا أكثر توافقا وأكثر ثقة بالنفس لته وأكثر قدرة علي المشاركة الإيجابية في حجرة الدراسة.

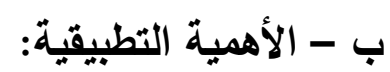
1 - إمداد للمكتبة بمقياس تتظيم الذات للاطفال المكفوفين. r-نوجه نتائج الدراسة الباحثين والعاملين في مجال المعاقين بصريا إلي أهم الأنشطة لتتمية مهارات تتظيم الذات من خلال تطبيق برنامج الدراسة.

$$
\text { مصطلحات الدراسة }
$$

الطفل الكفيف: يعرف إجرائياً بأنه الطفل الذي يعاني من قصور بصري تبلغ حدة

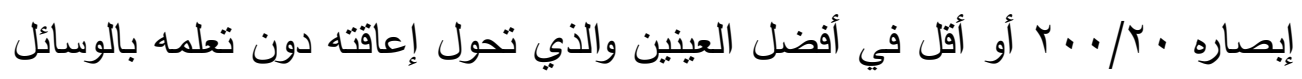

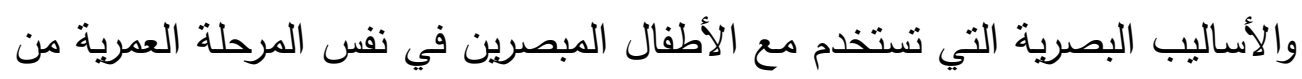
( 9 - r ا ( ) عاما ويعتمد علي الاستفادة من حواسه الأخرى في التعلم.

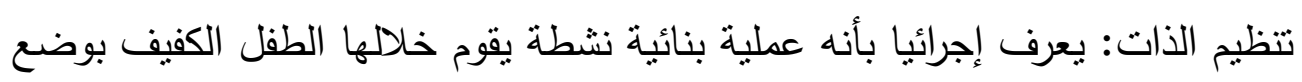

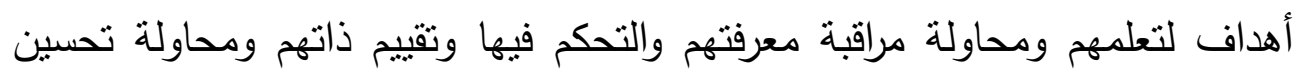
كفاءتهم الذاتية وتقاس بالدرجة التي يحصل عليها الطفل الكفيف علي مقياس تتظيم الذات للاراسة الحالية. البرنامج التدريبي: Training program: يعرف إجرائيا بأنه مجموعة من الخطوات المنظمة والمحددة يستتد إلي نظريات وفنيات وأدوات من الجلسات تهدف إلي تتمية بعض مهارات تتظيم الذات لدي الاطفال المكفوفين.

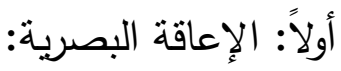




$$
\text { ( أ ) مفهوم الإعاقة البصرية: }
$$

هنالك ألفاظاً مثل: الأعمى، الأكمه، الضرير ، العاجز، أما الثخص الذي فقد بصره جزئياً كالأعشى وأصل كلمة أعمى أو مادتها هو العماء. r- بن المنظور الطبي:

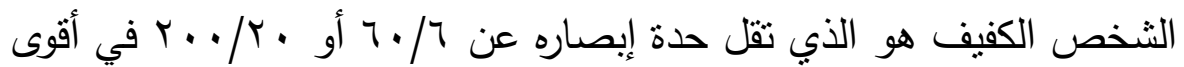
العينين بعد التصحيح، أي الحجم الذي يراه الإنسان العادي على مسافة .7 مثز يجب أن يقرب إلى 7 منز. والكفيف طبياً هو ذلك الشخص الذي لا بستطيع الرؤية

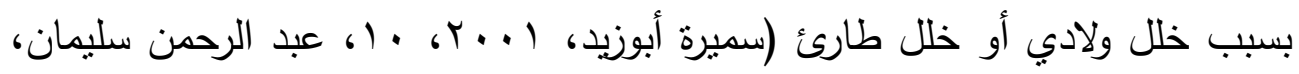
.$(7.6) 999$ ع- من المنظور التربوي: - من

هو ذلك الثخص الذي يتعارض ضعف بصره مع التعلم بصورة جيدة، ويجب

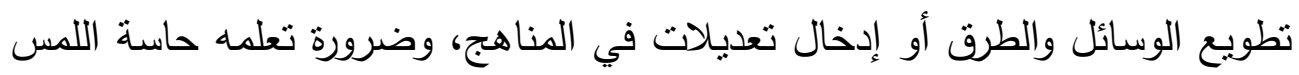
لتعلم القراءة والكتابة بطريقة برايل. (عبد الرحمن سليمان، 991 ( ) (ب) خصائص المعاقين بصرياً: 1- الخصائص اللغوية:

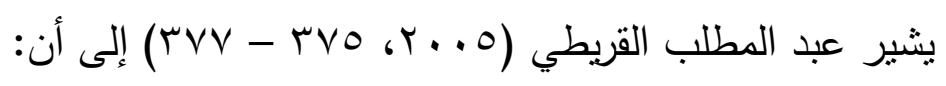
- تؤُثر على بعض مهارات الاتصال اللفظي. - الحرمان هن حاسة البصر لا يسمح للمعوق بصرياً تعلم الإيماءات والتعبيرات.

- يعاني المعاق بصرياً من اضطرابات اللغة والكلام؛ ويتمنت ذلك في:العلو ، عدم التغبير في طبقة الصوت، القصور في استخدام الإيماءات والتعبيرات الوجهية والجسمية المصاحبة، اللفظية.

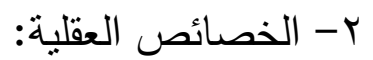


المقارنة بين ذكاء المبصرين والمكفوفين يرجع إلى المقاييس الإحصائية والتي أكدت على أنه لا يوجد فروق جوهرية بين ذكاء المبصرين والمكفوفين، وذللك على بلى إلى اختبار ستانفوردبينيه، والجانب اللفظي من مقياس وكسلر (عطية عطية محمد،

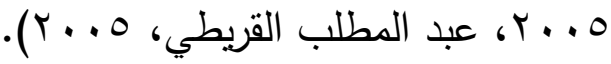

$$
\begin{aligned}
& \text { r- الخصائص الأكاديمية: }
\end{aligned}
$$

يشير بارو وآخرون . Buhrow, et al (1991) أن الأطفال من ذوي الإعاقة

البصرية يعانون من نقص في الكفاءة الأكاديمية بالمقارنة بأقرانهم المبصرين.

ع- الخصائص النفسية والاجتماعية:

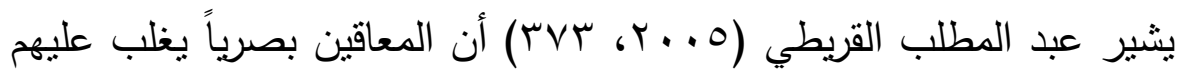
مشاعر الدونية، والقلق والصراع، وعدم الثقة بالنفس، والثعور بالاغتراب، وانعدام الأفق، والإحساس بالفنشل والإحباط، وانخفاض تقدير الذات، واختلال صورة الجسم،

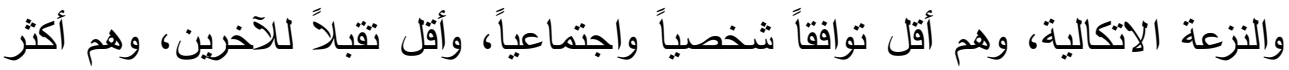

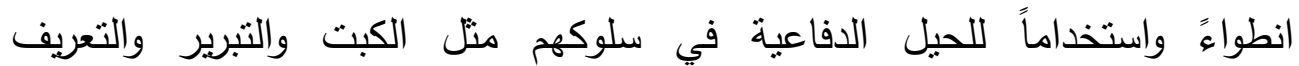
والانسحاب. ثانياً : تتظيم الذات: يشير هورنيك Hournic (1991) أن علماء النظرية المعرفية الاجتماعية ليسوا الوحيدون الذين تتاولوا طبيعة تتظيم الذات، وقد ناقش علماء السلوكية تتظيم الذات منل العديد من علماء النظرية المعرفية، وقد اعتمد العلماء الآخرون على لئه الأساس الذي وضعه علماء النظرية المعرفية الاجتماعية. ( أ ) مفهوم تتظيم الذات Self-Regulation:

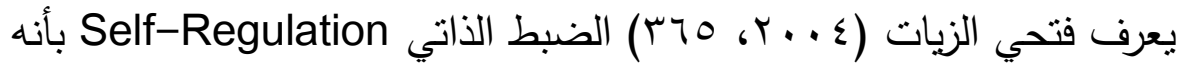
قدرة الفرد على التنظيم أو الضبط الذاتي لسلوكه في علاقته بالمتغيرات البيئية المتداخلة في المواقف، وبمعنى آخر تكييف سلوكه وبنائه المعرفي وعملياته المعرفية والمتغيرات البيئية بصورة منبادلة ومتفاعلة. 
وتعرف ريم ميهوب سليمون (T . . Y، Y0) تتظيم الذات على أنه عملية بنائية نشطة من خلالها يقوم المتعلمين بوضع أهداف لتعلمهم من خلالها يحاولون مراقبة

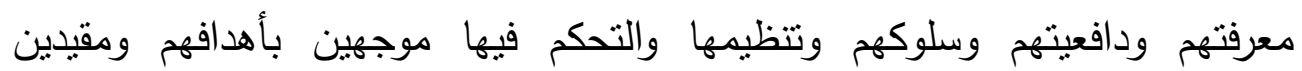
بالخصائص البيئية في السياق.

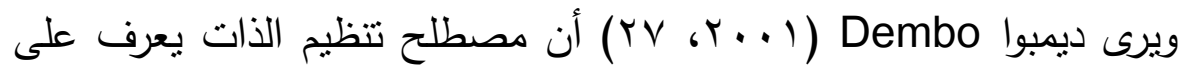

أنه قدرة الطلاب على التحكم في العوامل والظروف التي تؤثر على تعلمهم. من خلا عرض الباحثة لتعريفات التنظيم الذاتي يتضح ما يلي: 1- لإجادة الأطفال لتنظيم الذات يتطلب المشاركة الفعالة النشطة من جانب المتعلم ودور البيئة المحيطة في مساندة الإنجاز • r- تتظيم الذات مهارة يجب التدريب عليها وتعزيز فرص النجاح لدى المتعلمين. r- تأكيد بعض المفاهيم على ارتباط (SRL) بالنتائج المرتفعة والمتوقعة لجانب التحصيل الدراسي من خلال ممارسة اتقان العمليات المعرفية. ع- التنظيم الذاتي مكون شامل لعديد من العوامل المعرفية، ما وراء المعرفية، والدافعية، وما وراء الدافعية، والاجتماعية. (ب) نظريات تتظيم الذات: نظرية التعلم الشرطي الإجرائي skinner: تعد نظرية التعلم بالتعزيز أحد الجوانب المهمة في عملية التعلم المنظم ذاتياً، حيث تقوم هذه النظرية على كيفية تحديد الأفراد للاوافع وإمكانيات تعزيزها، والتتظيم الذاتي للتعلم يتعلق بالاختيار بين مختلف الأحداث، والاختيار يجب أن يكون صائباً وعلى أسس قوية؛ ففكرة اختيار ناتج مؤجل على ناتج حالي هي السمة المميزة لسلوك

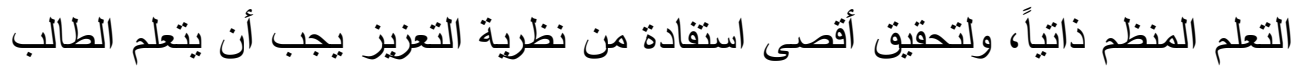
ممارسة العمليات الثانوية للنتظيم الذاتي مراقبة الذات Self-monitoring، التعليمات الذاتية Self-instruction، التعزيز الذاتي Self-reinforcement. 
1- التعليمات الذاتية Self-instructions: وهي إحدى الاستراتيجيات الفعالة لتعليم الأطفال إعطاء أنفسهر تعليمات توجيه سلوكياتهم، أوضحت دراسات أخرى أن التعليمات الذاتية فعالة في مساعدة التلاميذ على اكتساب اتجاهات أكثر ألثراه فعالية نحو المهام الأكاديمية، واكتساب مهارات اجتماعية أفضل وضبط سلوكياتهم الاندفاعية والعدوانية. (Halhan, 2007)

وقد حدد ميتشنبوم (9VV) خمس خطوات لتعليم الأطفال كيفية إعطاء أنفسهم تعليمات لتوجيه سلوكياتهم؛ وهي: - النمذجة المعرفية: يؤدي الراثد (النموذج) المهمة المطلوبة مع نطق التعليمات التي توجه الأداء. - التوجيه الظاهري الخارجي: يؤدي الطفل المهمة مع الاستماع إلى نطق الراشد للتعليمات. - - التوجيه الذاتي الظاهري: يكرر الطفل التعليمات بصوت مرتفع وهو يؤدي المهمة. - - التوجيه الذاتي الخافت: يههس الطفل بالتعليمات وهو يؤدي المهمة. - التعليم الذاتي المستتر : يفكر الطفل في صمت في التعليمات وهو يؤدي

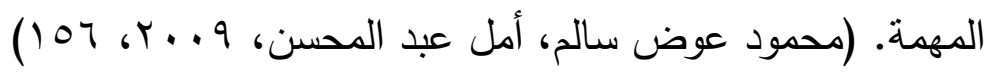
r- مراقبة الأات Self-monitoring: من الأساليب الأخرى التي قد تساعد الثخص على ضبط سلوكياته هي ملاحظة وقياس استجاباته بالضبط، متلما يقيس أي شخص آخر من خلا التحليل التطبيقي للسلوك، وتسجيل الاستجابات غالباً ما يكفي لتغيير مرات حدوث السلوك، أي هي عملية انتباه ذاتي متعدد لجوانب السلوك الثخصي، غالباً ما يتم تسجيل وتدوين لمدى تكرار وتركيز ذلك الانتباه .(Schunk, 1998) ويمكن إجراء مراقبة الذات في الفصل الدراسي بإعطاء تلاميذ لديهم صعوبة في تركيز الانتباه عند أداء واجباتهم مسجلات تصدر أصوات بسيطة كل 0 كـ ثانية عندما يسمع الطلاب هذه الأصوات يسأل نفسه: هل أركز انتباهي في المهمة؟ وهذا 
(Belfur, Hournek, الأسلوب أدى إلى زيادة انتباههم وإنتاجهم في أداء الواجبات

r- التعزيز الذاتي Self-reinforcement: يؤكد أصحاب نظرية التعلم

الإجرائي على أن مكافأة الاستجابة الإجرائية يجعلها أكثر احتمالاً للحدوث مرةً أخرى

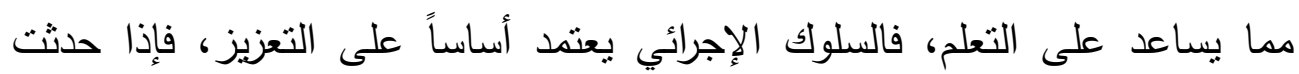

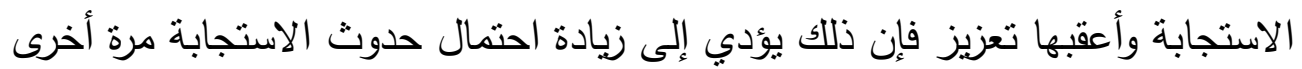

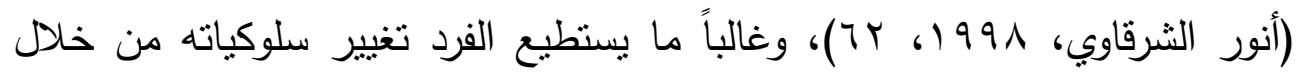

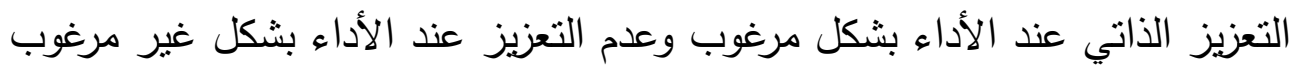
فيه (Masy, et al., 1989).

وعلى سبيل المثال بستطيع التلاميذ منخفضي التحصيل من تحسين الأداء

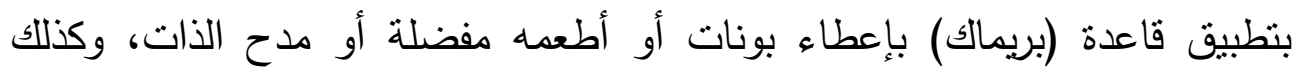
التعزيز المقدم من المعلم أو الوالدين. ( ج ) العوامل المؤثرة على تتمية تنظيم الذات لدى المعاقين المعاقين بصرياً:

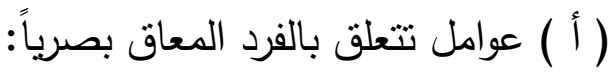

ا- انخفاض الكفاءة الذاتية بالمقارنة بالعاديين: يشير جورجي Gourgey

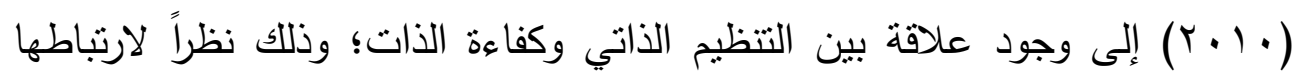

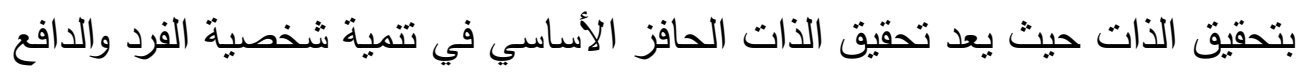
الأساسي إلى الإنجاز والتنظيم الذاتي. r- تدني مفهوم الذات لاى المعاقين بصرياً: حيث يثير (كمال سالم،

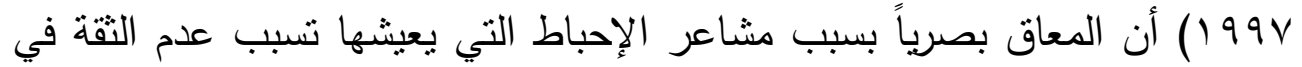
قدراته الذاتية، واعتماده على الآخرين بشكل كبير، والنقص في الخبرات الناجحة التي لتي

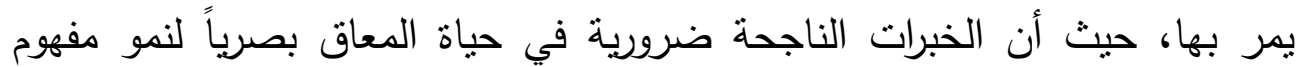
الذات، وبالنالي القدرة على الدافعية للتعلم والميل لتنظيم الذات. r- انخفاض الدافعية للتعلم: ومن أسبابها عدم استخدام أساليب التعلم الفعالة

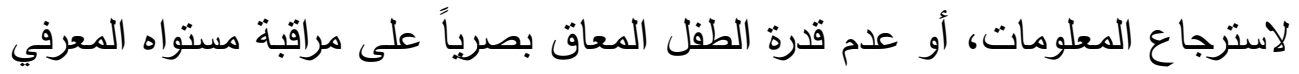


الحالي، عدم قدرة الطفل المعاق بصرياً على التركيز الفعال أو أداء المهام التعليمية، (Druden, Jefferson, عدم تدريب الأطفال على معارف ومهارات ما وراء المعرفة

ع - تدني المستوى الأكاديمي والمهني بالمقارنة بالعاديين: بسبب عدم القدرة على تحديد أهداف التعلم، والتخزين في الذاكرة، وعدم الاستفادة من التخذية الراجعة، بالهي وعدم القدرة على الاستفادة من الأفكار المطروحة أو الاستتناجات من الأفكار المطروحة (Oakhill, J, 1993).

(ب) عوامل تتعلق بالبيئة الخارجية: وهي تتصل بالظروف التي تربى ونشأ فيها الطفل المعاق بصرياً، وأساليب التربية وظروف التتشئة الاجتماعية. 1- النمط الأسري والعلاقات داخل الأسرة: من ترابط وتعاون بين الوالدين والأخوة يرتبط إيجابياً بكفاءة الذات؛ حيث التوجيه الصحيح للطفل بعد اكتشاف الإعاقة، أما الخلاف بين الوالدين بعد اكتشاف الإعاقة ترتبط سلبياً بكفاءة الذات لدى لئ لإه

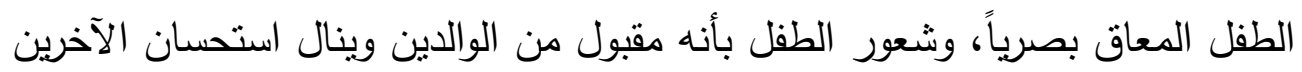
مما يجعله يشعر بالقيمة والكفاية الجسدية والاجتماعية واللغوية يساعد على شعوره

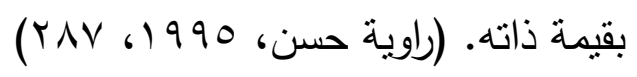

r- التذخل المبكر: يعتبر اهتمام الأسرة بالتدخل المبكر في المرحلة الحساسة من حياة الطفل من تتمية مهارات الاتصال والتوجيه الصحيح للطفل وتسهيل عملية التواصل بين الوالدين والطفل يدعم مشاعر الثقة بين الوالدين وأطفالهم المعاقين؛ وبالتالي يساعد ذلك على زيادة كفاءة الذات، كما تساعدهم على تقبل ذاتهم، وبالتالي تكسبهم مهارات تتظيم الذات منذ صغرهم (Blaiser, K., 2012, 273 (279). r- أساليب التربية المتبعة مع المعاق بصرياً: وتتمنل أساليب التربية من جانب المعلمين في: - إتاحة تدريب الأطفال المعاقين بصرياً على فرص الملاحظة والخبرة النفسية لأنها تترك أثراً كبيراً على إمكانية معرفة وإدراك العلاقات القائمة 
(Beach, et al., 1995, 531 على الشكل والحجم والوضع في الفراغ

- - إتاحة فرص ممارسة الأنشطة التربوية التي تساعد على بث الثقة بالنفس

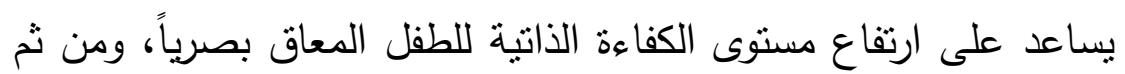
اكتساب مهارات تتظيم الذات.

- القدرة على تعويض الطفل المعاق بصرياً عن الصور البصرية والتي تشكل أهم ميكانيزمات تخزين المعلومات؛ ولذلك لا بد من تفويض المعاق بصرياً عن طريق تقديم التغذية الراجعة، وتقديم أسلوب التعلم النشط .(Jakson, 1996)

مما سبق تؤكد الباحثة على أهمية الاكتشاف المبكر للإعاقة وتوجيهها التوجيه الصحيح من تربية وتدريب، وأهمية إرشاد الأسرة بأساليب التربية الصحيحة تؤثر إيجابياً على تقبل الذات للطفل المعاق بصرياً؛ وبالتالي ترتفع كفاءته الذاتية وقدرته بالهاليه على اكتساب مهارات التنظيم الذاتي منذ صغره. ثالثاً: برنامج تدريبي يعتمد على الأنشطة اللاصفية:

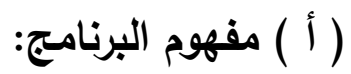

يعرف البرنامج بأنه: محتوى تربوي منظم يتضمن العديد من الخبرات

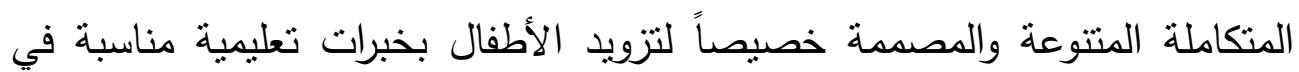
مناخ معد إعداداً مناسباً لتحقيق الأهداف (Courtis, 2002, 34). وهو مجموعة من الأنشطة والألعاب والممارسات العملية التي يقوم بها الطفل تحت إثراف وتوجيه الباحثة، وتعمل على تزويده بالخبرات والمعلومات والمفاهيم والاتجاهات التي من شأنها تدريبه على أساس التفكير السليم وتساعده على حل

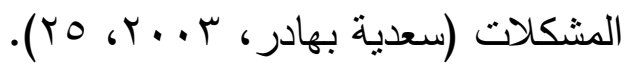

وتعرفه الباحثة بأنه مجموعة من الخبرات التربوية والتي يتم تقديمها للطفل الكفيف في صورة أنشطة مخطط لها تتضمن مجموعة من المهارات والخبرات والمعارف بهدف اكساب الطفل مفاهيم أو مهارات حسب أهداف البرنامج. 


\section{( ) (ب ) مفهوم الأنشطة:}

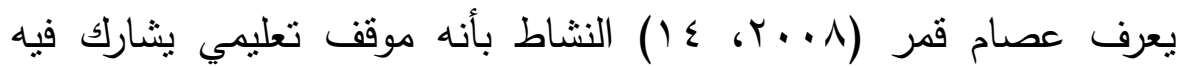
التلميذ لإثباع حاجاته وتحقق أهدافه مرغوبة، والأنشطة تكون مصاحبة للمواد

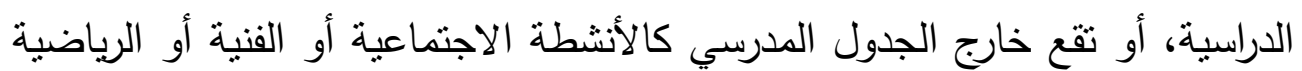
أو الثقافية.

كما يعرف النشاط بأنه مجال لخبرات متتوعة تؤدي إلى إحداث تغيير في

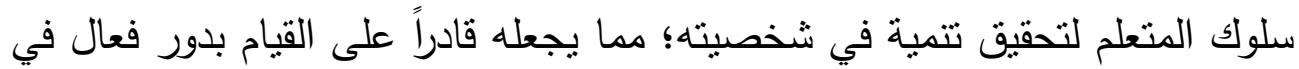
المجتمع. ومن خلال عرض الباحثة للتعريفات السابقة قد اتفقت على مجموعة من

$$
\text { الأسس يجب مراعاتها عند إعداد النشاط وهي كالآتي: }
$$

(Y) تتاسب مع خصائص المتعلمين وميولهم ورغباتهم، وتعمل على إثباع

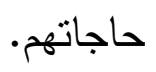

(ب) يجب أن تكون مخططة؛ وذلك في ضوء أهداف العملية التعليمية. (ع) يجب توافر الإمكانات المادية والبشرية اللازمة لإعدادها. (0) لا تتعارض مع البرنامج التعليمي للمؤسسة التعليمية، ولكنها تتكامل معه. دراسات سابقة: دراسات تناولت دور البرامج التدريبية في تنمية تنظيم الأت لاى الأطقال المعاقين بصرياً دراسة براون (2000) Brown. بعنوان: "ثقيبم برنامج تدربي على مانى

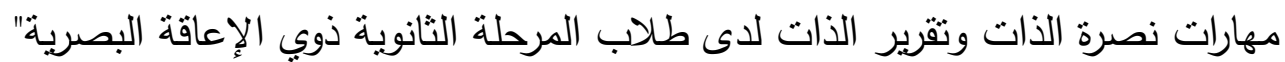
وهدفت الدراسة الكثف عن فاعلية برنامج تدريبي لتتمية مهارات نصرة الذات

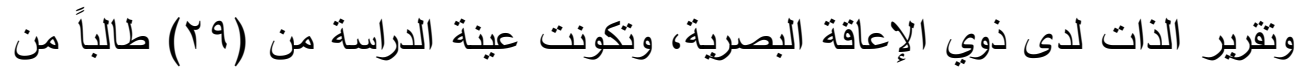
طلاب المرحلة الثانوية نم تقسيمهم لمجموعتين تجريبية قوامها (10) طالباً ومجموعة 
ضابطة عددها (ع ( ) لم يتعرض للبرنامج التدريبي، واستخدمت مقياس التتظيم الذاتي.

وأسفرت نتائج الدراسة عن: كان للتدريب أثز إيجابي لدى أفراد المجموعة التجريبية.

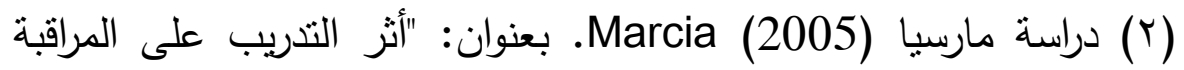

الذاتية للأطفال ذوي الإعاقة البصرية"

وهدفت الدراسة الكثف عن تأثير التدريب على المراقبة الذاتية في الأداء

الأكاديمي للأطفال ذوي الإعاقة البصرية، وتكونت عينة الدراسة من (9) أطفال (v) ذكور (r) إناث.

$$
\text { وأسفرت نتائج الدراسة إلى: }
$$

أ ) تأثير التدريب على المراقبة الذاتية على الأداء الأكاديمية للأطفال

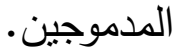

ب) أهمية المراقبة الذاتية في حجرات الدراسة بالنسبة للأطفال ذوي الإعاقة

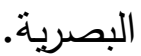

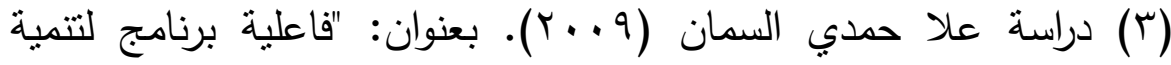

استراتيجيات تتظيم الذات لدى طلاب الجامعة"

وهدفت الدراسة التعرف على فاعلية برنامج في تتمية استراتيجيات التعلم

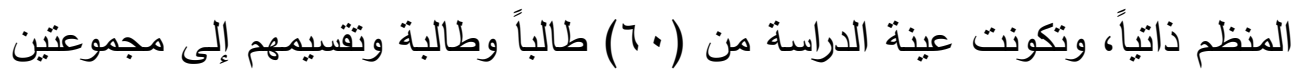
تجريبية وضابطة، واستخدمت مقياس الاستراتيجية المعرفية من إعداد الباحثة، وبرنامج الدراسة للباحثة، ومقياس التعلم المنظم ذاتياً من إعداد السيد خيري. وأسفرت التهر نتائج الدراسة إلى أنه توجد فروق ذات دلالة إحصائية عند مستوى (1 ...) بين المجموعة التجريبية والهجموعة الضابطة على أبعاد مقياس الاستراتيجية المعرفية ومقياس تتظيم الذات وذلك بعد تطبيق البرنامج لصالح المجموعة التجريبية.

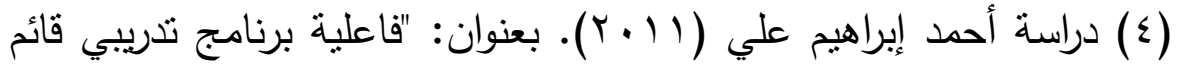

على رياضة الدفاع عن النفس لتتمية المعرفة الذاتية للأطفال المعوقين بصرياً" وهدفت الدراسة الكثف عن فاعلية برنامج على رياضة الكيك بوكسيج في تتمية المعرفة الذاتية المرتبطة بمتغيرات الإدراك الحسي للمعاقين بصرياً، وتكونت 


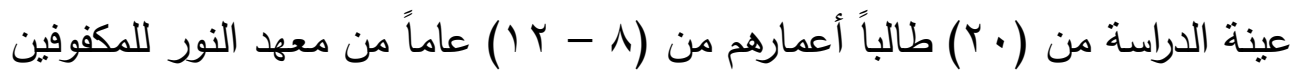
بمدينة الرياض تم اختيارهم بالطريقة القصدية تم توزيعهم على مجموعتين تجريبيتين بالتشاوي مع تكافؤ العمر • وقد توصلت نتائج الدراسة إلى فاعلية البرنامج في تتمية المعرفة الذاتية للمعاقين بصرياً، وكذلك فاعلية البرنامج في تتمية القدرات الإدراكية الحركية في مرحلة الطفولة المبكرة. وتوصي الدراسة بأهمية توظيف مبادئ رياضة الكيلك بوكسينج في مجال رياضة ذوي الإعاقة البصرية كرياضة معدلة يمكن الأخذ بها عند وضع البرامج الحركية للمعوقين بصرياً. دراسة سالمة راشد الحجي (11) • (1). بعنوان: "فعالية برنامج إرشادي جمعي في تتمية تقدير الذات لدى المعاقين بصرياً" وهدفت الدراسة إلى الكثف عن فاعلية برنامج إرشادي جمعي في تتمية تقدير

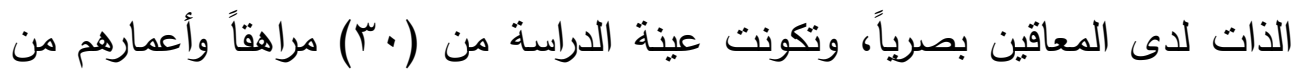

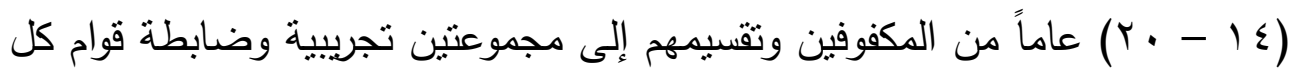
منها (·r) طالباً، واستخدمت أدوات مقياس تقدير الذات للباحثة. وأسفرت نتائج الدراسة إلى وجود فروق دالة إحصائياً بين درجات تقدير الذات لدى المجموعتين التجريبية والضابطة لصالح المجموعة التجريبية.

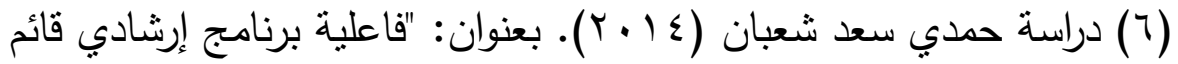
على استراتيجيات التظظيم الذاتي في تتمية الذكاء الوجداني لدى الأطفال ذوي الإعاقة البصرية"

هدفت الدراسة التعرف على العلاقة بين مكونات التنظيم الذاتي والذكاء الوجداني للمكفوفين ومدى فعالية البرنامج المستخدم في تتمية التظظيم الذاتي. وتكونت عينة الدراسة من (·r) طالباً من ذوي الإعاقة البصرية وأعمارهم من (ه.ب (1 1V.0) في المراحل الإعدادية والثانوية من معاهد النور للمكفوفين بمدينة طنطا. واستخدمت أدوات مقياس التنظيم الذاتي وثُرجم بلغة برايل، والبرنامج المقترح من إعداد 
الباحث. وتوصلت نتائج الدراسة إلى فعالية البرنامج المستخدم في تتمية التنظيم الذاتي وتحسين الذكاء الوجداني لدى عينة الدراسة ذوي الإعاقة البصرية. من خلال عرض مشكلة الدراسة والإطار النظري لها يمكن صياغة فروض الدراسة كما يلي: (1) توجد فروق دالة إحصائياً بين منوسطي رتب درجات الأطفال في المجموعة التجريبية في القياسين القبلي والبعدي وذلك لصالح القياس البعدي في مقياس تتظيم الذات.

(Y) توجد فروق دالة إحصائياً بين متوسطات رثب درجات الأطفال بالمجموعتين التجريبية والضابطة وذلك بعد تطبيق البرنامج على مقياس تتظيم الذات وأبعاده، وذلك لصالح أطفال المجموعة التجريبية. (r) لا توجد فروق دالة إحصائياً بين متوسطات رثب درجات الأطفال بالمجموعة التجربيية في القياس البعدى والقياس التتبعى على مقياس تتظيم الذات للأطفال المكفوفين.

جلسات البرنامج الخاصة بالمهارات الحياتية

\begin{tabular}{|c|c|c|c|c|c|c|}
\hline التقويم & والأدواتئل & محتوى الجلسة & |الأشطة & المستخدمة & عنوان الجلسة & رقم \\
\hline- & كروت بارزة & 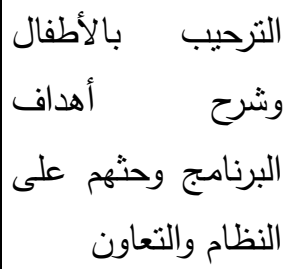 & & التعزيز & افتعارف & 1 \\
\hline القتب كلمات البحزئ & | & 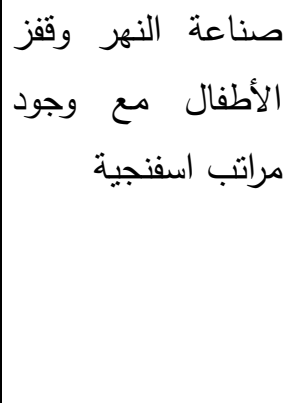 & رياضي & المالمات النمزية & النهز & r \\
\hline
\end{tabular}




\begin{tabular}{|c|c|c|c|c|c|c|}
\hline التقويم & الأدوات & محتوى الجلسة & الأنشطة & الفنيات & عنوان الجلسة & رقم \\
\hline & كلمات بارزة & & & & & \\
\hline الكتب: الرياضة تتمي & بحروف & 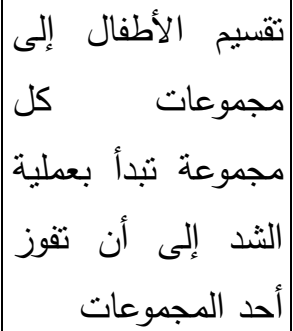 & |رياضي & التمنيز & مسابقات شد & r \\
\hline العائزة المجموعة & |سفاتب & مجموعات & رياضي & التمنيز & العدو & $\varepsilon$ \\
\hline التب التب شكلتياء & طلصال & 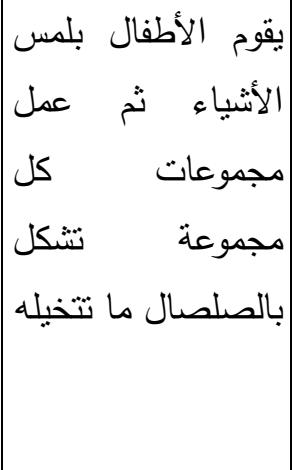 & فني & التمذاجة التمزيز & لوحة الأشكال & 0 \\
\hline مهنة الصيد & 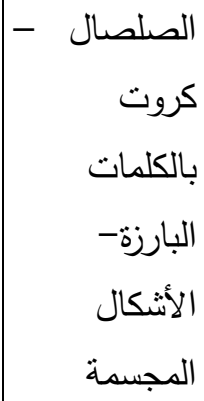 & |الثباك - محاكاة & قصصي & 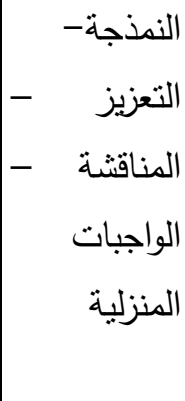 & |البيئة & 7 \\
\hline
\end{tabular}




\begin{tabular}{|c|c|c|c|c|c|c|}
\hline التقويم & والأدوات & محتوى الجلسة & |لأنشطة | & الفنيات & عنوان الجلسة & رقم \\
\hline وتظ الأغنية منهم & 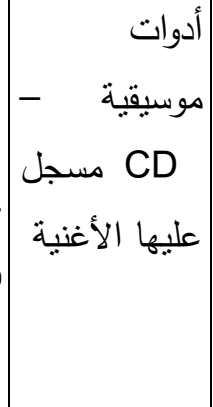 & | بالموسيقى $\quad$ الإيقاعية & روياضي & التمذجة & الآثار & V \\
\hline |تحارثت & - مبات & | الحبال & رياضي & المناقنة النمزيز & أهمية & $\Lambda$ \\
\hline قصدة & | & 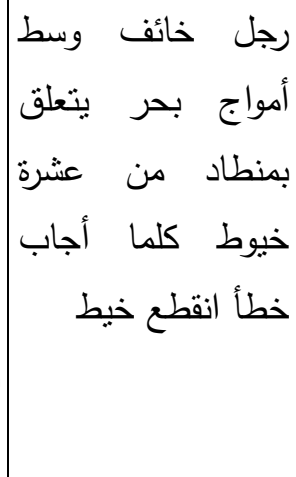 & قصصي & 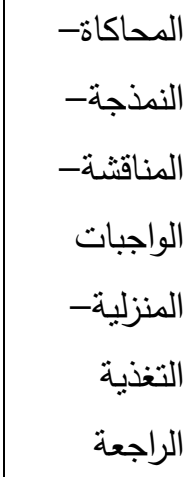 & الرجل الخائف & 9 \\
\hline قصدة الأسرة & | لمليها & تشتوبت & قصصي & 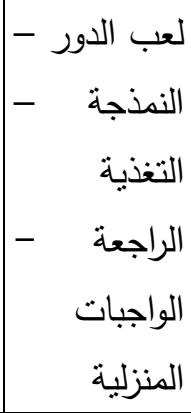 & الأسرة & 1 . \\
\hline كتابة & صلصال & تتحدث الباحثة عن & ثقافي & المحاكاة - الماة & حديقة & 11 \\
\hline
\end{tabular}




\begin{tabular}{|c|c|c|c|c|c|c|}
\hline التقويم & الأدوات & محتوى الجلسة & |الأنشطة & المستخدمة & عنوان الجلسة | & رقم \\
\hline سمعت & |ل & لميوانات الحديقة، مع المجسمات & & المناقتة & | الحيوان & \\
\hline اكتب أسماء & كبوانات & البالاستيكية & ثقافي & - المناقة النمذة & البيئة & IT \\
\hline كع حفابة الأغنية & 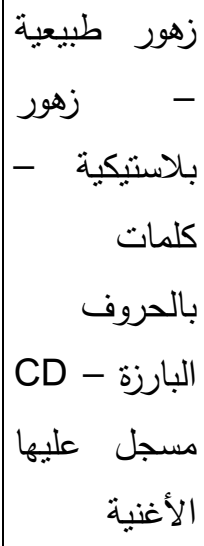 & 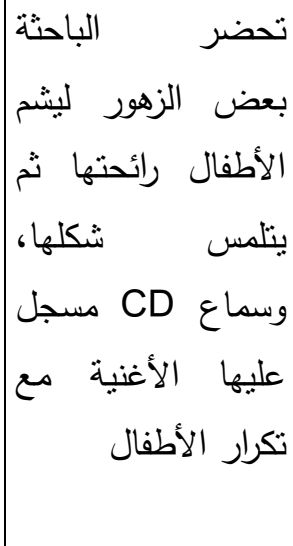 & موسيقي & - التمذية & حديقة الزهور & T \\
\hline كتابة بعض & | شتشبي & معت & فني & 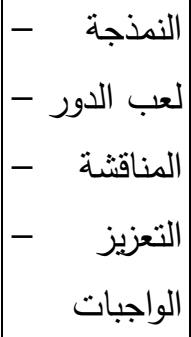 & التعرف على & $1 \leq$ \\
\hline
\end{tabular}




\begin{tabular}{|c|c|c|c|c|c|c|}
\hline التقويم & الأدوات & محتوى الجلسة & |الأنشطة & الفنيات & عنوان الجلسة & |رقم \\
\hline & بكلمات بارزة & وتمثتخل دور كل منهم كن من & & نززلية ل & & \\
\hline 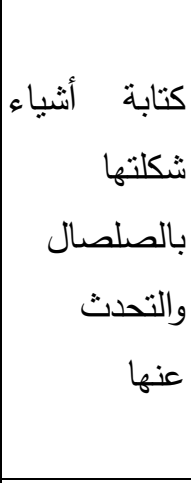 & كلصال & نماقدة & |قصصي & الت التعزيز & بالصلصال التشكيل الحر & 10 \\
\hline مارستها اليوم & طبط مناسب & 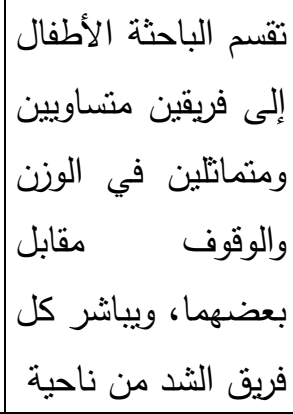 & رباضي & 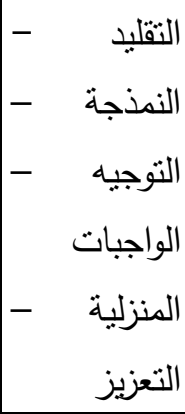 & لعبة الحبل & 17 \\
\hline مارستها اليوم & قأطراق & 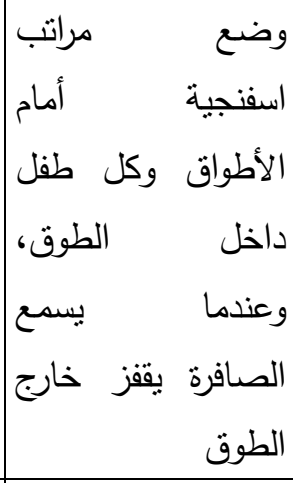 & رياضي & 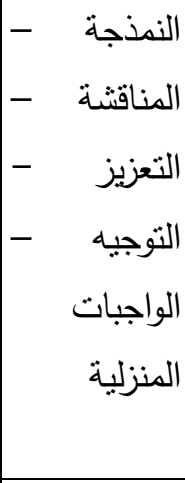 & الأطواق & 18 \\
\hline كع كفابة الأغنية & 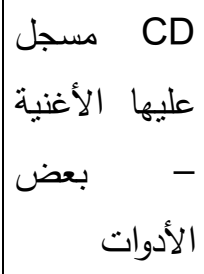 & 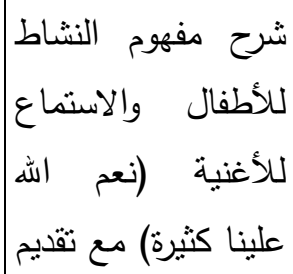 & موسيهي & التعزيز & |الموسيقية & \\
\hline
\end{tabular}




\begin{tabular}{|c|c|c|c|c|c|c|}
\hline التقويم & والأدواث & محتوى الجلسة & الأنشطة & الفنيات & عنوان الجلسة & رقم \\
\hline & الموسيقية & التغذية الراجعة & & المنزلي & & \\
\hline تحياة الجنود & عليها م القصة & 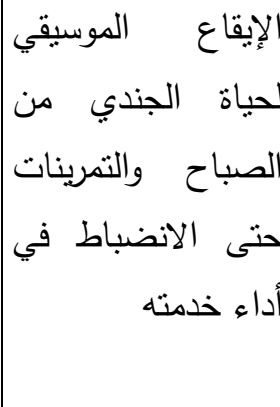 & قصوسيقي & 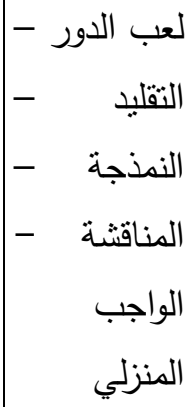 & جيوم في حياة & 19 \\
\hline تصدة ليلى & مليها & منأنساً & |قصصي | & 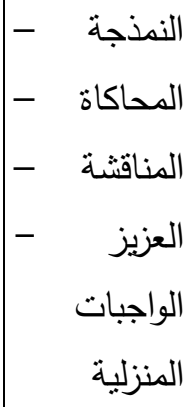 & قصة & \\
\hline
\end{tabular}

إجراءات الدراسـة:

منهج الدراسة:

اعتمدت الدراسة الحالية على المنهج التجربيي، وقد اعتمدت الباحثة على

التصميم ذي المجموعتين المنكافئتين (التجريبية والضابطة) بوصفه أحد التصميمات المناسبة لاختبار صحة الفروض ودراسة أثر متغير على متغير آخر، وذلك بالقياس القبلي والبعدي، وهذا المنهج يلائم طبيعة الدراسة الحالية من حيث محاولتها التحقق من فاعلية البرنامج التذريبي في تتمية المهارات الحياتية وتتظيم الذات لدى الأطفال المكفو فين.

عينة الدراسـة:

تكونت عينة الدراسة في صورتها النهائية من (ب) طفلاً من الأطفال المكفوفين ممن نتراوح أعمارهم من 9 - Y I عاماً، ومتوسط أعمارهم (07. . 1 ) سنة 
بانحراف معباري قدره (Vr. (1)، ودرجة فقد البصر الكلي، وقد نم تقسيمه عشوائياً إلى مجموعتين هما:

[1] مجموعة ضابطة: مكونة من (• (1) من الأطفال المكفوفين لم يطبق عليها البرنامج

[Y] مجموعة تجريبية: مكونة من (·) (1) من الأطفال المكفوفين وهذه المجموعة التي تم تطبيق البرنامج التدريبي المستخدم في الدراسة الحالية عليها. أدوات الدراسة:

تستخدم الباحثة مجموعة من الأدوات، أدوات تحقيق التكافؤ بين مجموعتي الدراسة، وأدوات أخري لقياس متغيرات الدراسة بالإضافة إلي البرنامج التدريبي المستخدم ويمكن تصنيف تلأك الأدوات إلى:

1- أدوات ضبط العينة وتحقيق التكافؤ بين مجموعتيها: وتتضمن:

اختبار ستانفورد بينيه الصورة الرابعة تعريب لويس مليكة ( 1991 ) ) (ب) مقياس المستوي الاجتماعي الاقتصادي للأسرة إعداد عبد العزيز

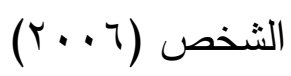

r- أدوات قباس متغيرات الدراسة:

أ- مقياس نتظيم الذات للأطفال المكفوفين ( إعداد الباحثة )

ج - برنامج تدريبي لتتمية تتظيم الذات للأطفال المكفوفين ( إعداد الباحثة) الأساليب الإحصائية المستخدمة: يتم استخدام الأساليب الإحصائية التالية:

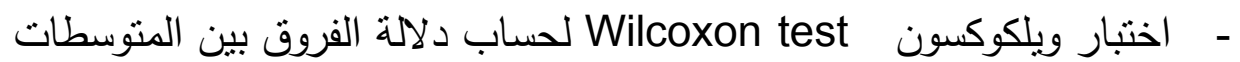
بالنسبة للمجموعات المرتبطة. - اختبار مان ويتتي Mann-whtney test لحساب دلالة الفروق بين المتوسطات بالنسبة للمجموعات المستقلة. - قيمة (Z) لحساب قيمة الفروق بين متوسطات رتب المجموعتين. 
(') توجد فروق دالة إحصائياً بين متوسطات رتب درجات الأطفال في المجموعة التجريبية في القياسين القبلي والبعدي، وذللك لصالح القياس البعدي في مقياس تتظيم الذات.

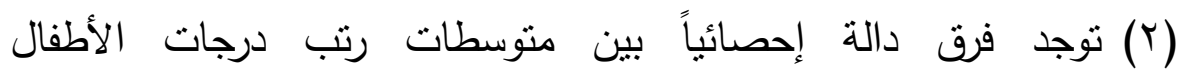
بالمجموعتين التجريبية والضابطة وذلك بعد تطبيق البرنامج على مقياس

$$
\text { مهارات نتظيم الذات وأبعاده. }
$$

(ץ) لا توجد فروق دالة إحصائياً بين منوسطات رتب درجات الأطفال بالمجمعة التجريبية في القياس البعدي والقياس التتبعي على مقياس مهارات تتظيم الذات.

توصيات الدراسة: في ضوء ما أسفرت عنه نتائج الدراسة توصي الباحثة بالآتي: - إسناد الأنشطة والإثراف عليها لمعلمين متخصصين والاهتمام بإعداد المعلم في المعاهد والكليات المتخصصة. - توجيه الاهتمام بإعداد برامج الأنثطة التي تتتاسب مع الأطفال المكفوفين وتتجيعهم على ممارستها؛ لبقاء أثز التعلم المتمركز حول الطفل. - ضرورة التتوع في الأنشطة وتكاملها، ويتفق ذلك مع مبدأ تنربوي هام وهو التهاه

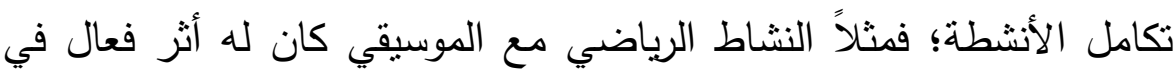
عملية التواصل بين الأطفال المكفوفين. - ضرورة إعداد المواد والوسائل التعليمية التي تنتاسب مع خصائص وحاجات

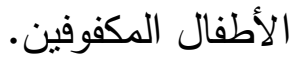
- ضرورة الاستفادة من التكنولوجيا الحديثة والتي تساعد على سرعة التعلم والاستدعاء من الذاكرة، منل الكمبيوتز وبرامجه. - البعد عن الوسائل النقليدية في التدريس للمكفوفين والاهتمام بالوسائل الملموسة لتعويض فقد البصر . - التدرج في تقديم الخبرات للأطفال مع الاهتمام بالتعزيز المناسب في كل خبرة 
- - إعطاء الوقت الكافي والمناسب في عملية التدريب والتدرج في تقديم الخبرة من الأسهل للأصعب.

- عند تقديم الخبرات المباشرة للأطفال المكفوفين ضرورة تقسيمه إلى مستويات ووضع برامج ومقررات وأنشطة تتناسب مع كل مستوى، وتقديم التعزيز المادي والمعنوي له. - العمل على بث الثقة في نفوس الأطفال المكفوفين وتعزيز قيم النجاح والمثابرة لديهم. - - ضرورة الاعتماد على الأنشطة في التعلم لما لها من أثر في مساعدة الأطفال

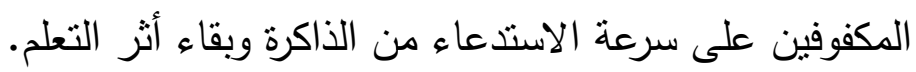


المراجع:

أولاً: المراجع العربية: (براج:

إبراهيم فراج (T · . ب). أثر برنامج للتدريب علي بعض المهارات الحياتية في مفهوم الأات لاي الاطفال المتخلفين عقليا القابلين للتعلم. رسالة دكتوراة، كلية التربية، جامعة الازهر .

أحمد إبراهيم علي (11 + (1). فاعلية برنامج تلريبي قائم على رياضة الافاع عن النفس لتنمية المعرفة الأتية للأطفال المعاقين بصرياً. مجلة كلية

$$
\text { التربية، جامعة بور سعيد، r (9)، ج (1) يناير (1) (1) (1). }
$$

أنور الثرقاوي (991)). التعلم - نظريات وتطبيقات. ط (0)، القاهرة، مكتبة

$$
\text { الأنجلو المصرية. }
$$

بسنت جلال (7 ا • r). البروفيل الثخصي للأكاءات المتعددة للطقل الكفيف وأثر برنامج قائم علي الأكاءات لتمية دافعية للتعلم والمهارات الحياتية .

رسالة دكتوراه، كلية الدراسات العليا للتربية، جامعة القاهرة.

حمدي سعد شعبان (ع ( • ( ). فاعلية برنامج قائم على استراتيجيات تنظيم الذات في تنمية الأكاء الوجداني لاى الأطفال ذوي الإعاقة البصرية. رسالة دكتوراة (غير منشورة)، معهد الدراسات التربوية، جامعة القاهرة. راوية حسن الدسوقي (990) (190). فعالية الأات وعلاقتها بأحداث الحياة الضاغطة ويعض الاضطرابات. مجلة كلية التربية، جامعة الزقازيق، العدد الرابع

$$
\text { والعشرون، الجزء الأول. }
$$

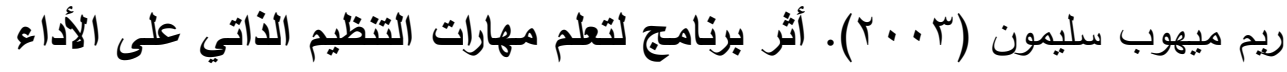
الأكاديمي لاى عينة من طلاب الجامعة. رسالة دكتوراة (غير منشورة)، كلية التربية، جامعة طنطا. سالمة راشد الحجي (11 +r). فعالية برنامج إرشادي جمعي في تنمية تقدير الذات

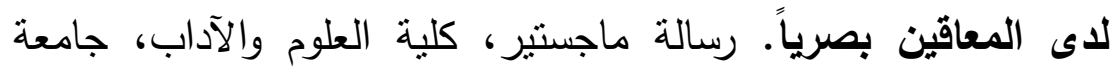
نزوي، سلطنة عمان. 
سعدية بهادر (r . . r). برامج تربية أطفال ما قبل المدرسة. عمان، دار المسيرة. سميرة أبو زيد النجدي (1 (. ب). فنون المعوقين وطرق تدريسها. القاهرة، مكتبة زهراء الشرق.

عبد الرحمن سيد سليمان (1991 (). سيكولوجية ذوي الاحتياجات الخاصة. القاهرة، مكتبة زهراء الثرق.

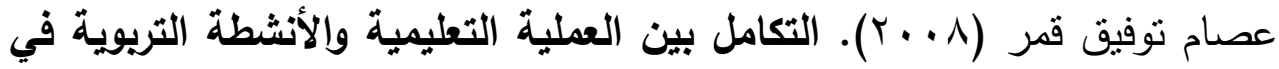
المدرسة الابتدائية. القاهرة: المكتب الجامعي الحديث.

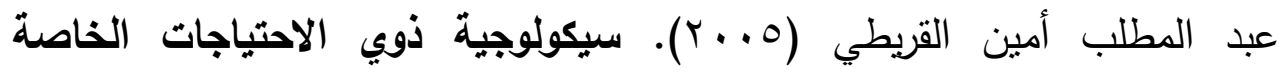
وتربيتهم. طع، القاهرة، دار الفكر العربي.

عطية عطية محمد (0.一). الضغوط النفسية لاى الكفيف وعلاقتها باتجاهات

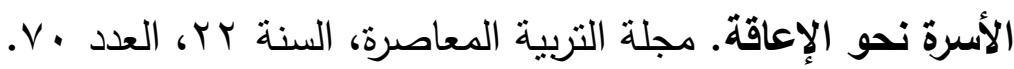
علا حمدي السمان (9 . . ب). فاعلية برنامج لتنمية استراتيجيات تنظيم الذات لاى طلاب الجامعة. رسالة دكتوراة، كلية التربية، جامعة سوهاج. فتحي مصطفى الزيات (ع . . ب). سيكولوجية التعلم بين المنظور الارتباطي والمنظور المعرفي. طب، القاهرة، دار النشر. كمال سالم سيسالم (997 (1). المعاقون بصرياً - خصائصهم ومناهجهم. القاهرة، الدار المصرية اللبنانية.

محمود عوض الله سالم، أمل عبد المحسن زكي (9 . . ؟). صعويات التعلم والتنظيم الأتي. القاهرة، دار اميتراك للنشر والطباعة والتوزيع.

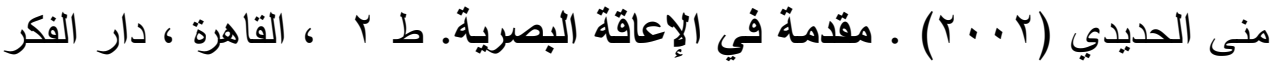
العربي. 


$$
\text { ثانياً: المراجع الأجنبية: }
$$

Belfiore, P. J. \& Hornyak, R. S. (1998). Operant theory and application to self-monitoring in adolescents in $\mathrm{D}, \mathrm{H}$ Schunk and J. Zimmerman (Eds), self-regulated learning from teaching to self-reflectivw practice. New York: Guilford press.

Beach, J., Robinet, J. \& Larson, J. (1995). Self-esteem and independent living skills of adults with visual impairment. Journal of visual impairment, blind, 89 (6), New York.

Blaiser, Kristina (2012). Supporting communication development of infants and toddlers with hearing loss. Seminars in speech and language, vol (33), Nov 2012.

Brown, Holly Annett (2000). An assessment of a selfadvocacy skills training program for secondary students with disabilities. PhD. University of Alabama.

Buharow, Hartshorne \& Sharon (1998). Parents and teachers racings of the social skills of elementary age students who are blind. Journal of visual impairment and blindness, vol. (92), No. (7).

Curtis, Audrey (2002). A curriculum for the preschool child. learning to learn, 2nd ed. London, Rout 1 edge. 
Dembo, M. H. (2002). Learning to teach is not enough future teachers also need to learn how to learn. Teacher education quarterly, 28 (4).

Dryden, M. A. \& Jefferson, P. (1994). Use of background knowledge and reading achievement among elm entry school students. Paper presented at the annual meeting of the American Educational Research Association, New York: Orleans.

Jackson, D. L., Ormrod, J. E. \& Salih, D., J. (1996). The nature of student metacognitive processes, reflected in their self-generated questions and class notes. Paper presented at the annual meeting of the American Educational Research Association, New York.

Marcia, Rock (2005). Use of strategic self-monitoring to enhance academic engagement productivity and accuracy of student's with in terventions. Journal of exceptional children, vol (7).

Massey, C. M. \& Gelman, R., R. (1989). Preschool ability to decide whether a photographed unfamiliar object can move itself. Developmental psychology.

Schunk, D., H. (1998). Teaching elementary student to selfregulate practice of mathematics skills with modeling. (Eds), self-regulated. 